\title{
Uncertainty and Variation of Remotely Sensed Lake Ice Phenology across the Tibetan Plateau
}

\author{
Linan Guo ${ }^{1,2,+} \mathbb{C}$, Yanhong $\mathrm{Wu}^{1,+}$, Hongxing Zheng ${ }^{3} \mathbb{C}$, Bing Zhang ${ }^{1,2, * \mathbb{C}}$, Junsheng $\mathrm{Li}^{1}$, \\ Fangfang Zhang ${ }^{1} \mathbb{D}$ and Qian Shen ${ }^{1}$ \\ 1 Key Laboratory of Digital Earth Science, Institute of Remote Sensing and Digital Earth, \\ Chinese Academy of Science, Beijing 100094, China; guoln@radi.ac.cn (L.G.); wuyh@radi.ac.cn (Y.W.); \\ lijs@radi.ac.cn (J.L.); zhangff07@radi.ac.cn (F.Z.); shenqian@radi.ac.cn (Q.S.) \\ 2 University of Chinese Academy of Sciences, Beijing 100049, China \\ 3 CSIRO Land and Water, Canberra, ACT 2601, Australia; Hongxing.Zheng@csiro.au \\ * Correspondence: zb@radi.ac.cn; Tel.: +86-10-8217-8002 \\ + These two authors contributed equally to this work.
}

Received: 24 August 2018; Accepted: 21 September 2018; Published: 25 September 2018

\begin{abstract}
In the Tibetan Plateau (TP), the changes of lake ice phenology not only reflect regional climate change, but also impose substantial ecohydrological impacts on the local environment. Due to the limitation of ground observation, remote sensing has been used as an alternative tool to investigate recent changes of lake ice phenology. However, uncertainties exist in the remotely sensed lake ice phenology owing to both the data and methods used. In this paper, three different remotely sensed datasets are used to investigate the lake ice phenology variation in the past decade across the Tibetan Plateau, with the consideration of the underlying uncertainties. The remotely sensed data used include reflectance data, snow product, and land surface temperature (LST) data of moderate resolution imaging spectroradiometer (MODIS). The uncertainties of the three methods based on the corresponding data are assessed using the triple collocation approach. Comparatively, it is found that the method based on reflectance data outperforms the other two methods. The three methods are more consistent in determining the thawing dates rather than the freezing dates of lake ice. It is consistently shown by the three methods that the ice-covering duration in the northern part of the TP lasts longer than that in the south. Though there is no general trend of lake ice phenology across the TP for the period of 2000-2015, the warmer climate and stronger wind have led to the earlier break-up of lake ice.
\end{abstract}

Keywords: lake ice phenology; Tibetan Plateau; inland water; climate change

\section{Introduction}

The Tibetan Plateau (TP) is a region sensitive to global climate change [1,2], and could trigger or amplify climate variation worldwide [3,4]. The numerous lakes in the TP not only play important roles in the climate system by affecting regional water and energy balance, but also are regarded as indicators of regional climate change [5]. Changes in climate factors such as air temperature and precipitation could directly affect the physical, chemical, and biological characteristics of lakes, in addition to conferring indirect effects through the modification of the surrounding watershed [6]. It has been reported that water level, surface area, and other properties of lakes in the TP have changed substantially in the past decades $[7,8]$. The formation and ablation of lake ice is one of the unique properties of lakes in the TP highly related to temperature variation $[9,10]$, and lake ice phenology is one of the most reliable and robust evidences reflecting global warming [11-14]. Changes in lake ice 
phenology in the TP are thought to be more representative of regional climate change as the lakes are located in a region with light human impact [15-17].

The changes of lake ice phenology have recently attracted more research interests $[9,18-21]$. Basing on ground observations, Magnuson et al. (2000) found that 39 lakes in the Northern Hemisphere showed consistent changes in ice phenology over the past 150 years with the later freezing-up and earlier breaking-up of lake ice [20]. The findings were further verified by other research studies [18,22-25]. Research on lake ice phenology based on ground observations are usually limited to a small spatial domain, due to the high costs of data collection and minimal available records. By contrast, remote sensing is capable of providing comprehensive and large-scale observation at different temporal-spatial resolutions for lake ice phenology investigation. Using optical remote sensing, researchers have successfully identified the lake ice phenology of various regions on the basis of data from different instruments like advanced very high resolution radiometer (AVHRR) sensor [19] and moderate resolution imaging spectroradiometer (MODIS) [15]. Some other researchers $[10,12,26-28]$ have tried to investigate the dynamics of lake ice by using microwave data (QuickSCAT, SSM/I, SMMR, AMSR-E). Based on passive microwave data, researchers are now able to measure lake ice phenology parameters, such as ice-cover duration [10,29]. Compared with microwave data, medium resolution optical remote sensing data have advantages in terms of higher temporal-spatial resolution and richer multispectral information [21]. In the currently available methods automatically extracting lake ice phenology from remotely sensed data, the threshold-based algorithm is widely used [30]. For example, Nonaka et al. (2007) defined a thermal temperature threshold together with MODIS NIR data to monitor the breaking-up dates of 18 big lakes in the Eurasian region with an estimation error less of than three days [31]. Latifovic and Pouliot (2007) used AVHRR data to monitor the ice phenology of 42 lakes by setting two critical values in classifying the NIR time series [19].

The Tibetan Plateau is a harsh nature barrier for ground observation [32]. Remotely sensed data is, therefore, more valuable for lake ice phenology investigation in the plateau. For example, based on eight-day MODIS snow cover data, Kropáček et al. (2013) showed the lake ice phenology trends of lakes in the Tibetan Plateau for the period of 2001 to 2010 [15]. Gou et al. (2017) used multiple MODIS data products to detect the lake ice phenology and its relation to the climate of Nam Co in the TP [21]. Though the current available methods based on different remotely sensed datasets have shown their merits in identifying lake ice phenology, uncertainties exist because of both the data and the algorithms.

This paper aims to investigate the changes of lake ice phenology in the Tibetan Plateau for the period of 2000 to 2015 by using the most recently available remotely sensed datasets and methods. Three different methods based on multiple MODIS data products are applied to 32 lakes across the Tibetan Plateau. The uncertainty of the results from different methods are assessed via the triple collocation approach. The temporal-spatial variation of lake ice phenology with respect to climate in the Tibetan Plateau is also discussed.

\section{Study Area and Data}

\subsection{Study Area}

The Tibetan Plateau (TP) is located between $26^{\circ} 00^{\prime}-39^{\circ} 47^{\prime} \mathrm{N}$ and $73^{\circ} 19^{\prime}-104^{\circ} 47^{\prime} \mathrm{E}$, with an area of about 2.5 million $\mathrm{km}^{2}$. It is the world's highest plateau, with a mean elevation over $4500 \mathrm{~m}$, and it is known as the "Asian water tower", contributing to most major rivers in Asia [8]. The climate of the TP is influenced by westerly winds in winter and by the Asian monsoon in summer [33]. It is dry and cold in winter, but humid in summer [34].

The total area of lakes in the plateau is around $45,000 \mathrm{~km}^{2}$, with 72 lakes larger than $100 \mathrm{~km}^{2}$ [35]. Most of the lakes are inland lakes located at the altitudes between $4000 \mathrm{~m}$ and $5000 \mathrm{~m}$ [34]. Among the 43 lakes with areas larger than $200 \mathrm{~km}^{2}$ [35], 32 lakes were selected for this research as we exclude the seasonal lakes and lakes of which data have too much cloud (Table 1 and Figure 1). 
Table 1. Selected lakes in Tibetan Plateau. Latitude, longitude, water level, and area were obtained from Wang and Dou [35]. Annual mean temperature is based on the nearest meteorological station from the China Meteorological Data Service Center (CMDC).

\begin{tabular}{|c|c|c|c|c|c|c|}
\hline Label & Name & Latitude (N) & Longitude (E) & Water Level (m) & Area $\left(\mathrm{km}^{2}\right)$ & Temperature $\left({ }^{\circ} \mathrm{C}\right)$ \\
\hline 1 & Har Lake & $38^{\circ} 12^{\prime}-38^{\circ} 25^{\prime}$ & $97^{\circ} 24^{\prime}-97^{\circ} 47^{\prime}$ & 4077 & 601.7 & -2.04 \\
\hline 2 & Ayakum Lake & $37^{\circ} 28^{\prime}-37^{\circ} 38^{\prime}$ & $89^{\circ} 04^{\prime}-89^{\circ} 36^{\prime}$ & 3876 & 537.6 & 3.90 \\
\hline 3 & Aqqik Kol & $36^{\circ} 58^{\prime}-37^{\circ} 10^{\prime}$ & $88^{\circ} 18^{\prime}-88^{\circ} 33^{\prime}$ & 4250 & 351.2 & 3.90 \\
\hline 4 & Qinghai Lake & $36^{\circ} 32^{\prime}-37^{\circ} 15^{\prime}$ & $99^{\circ} 36^{\prime}-100^{\circ} 47^{\prime}$ & 3194 & 4340 & 0.20 \\
\hline 5 & Jingyu & $36^{\circ} 14^{\prime}-36^{\circ} 27^{\prime}$ & $89^{\circ} 16^{\prime}-89^{\circ} 37^{\prime}$ & 4708 & 264 & 3.90 \\
\hline 6 & Lexie Wudan Lake & $35^{\circ} 41^{\prime}-35^{\circ} 49^{\prime}$ & $90^{\circ} 02^{\prime}-90^{\circ} 21^{\prime}$ & 4867 & 227 & -3.54 \\
\hline 7 & Hoh Sai Lake & $35^{\circ} 38^{\prime}-35^{\circ} 50^{\prime}$ & $92^{\circ} 37^{\prime}-93^{\circ} 03^{\prime}$ & 4475 & 254.4 & -4.60 \\
\hline 8 & Donggei Cuona Lake & $35^{\circ} 13^{\prime}-35^{\circ} 23^{\prime}$ & $98^{\circ} 20^{\prime}-98^{\circ} 43^{\prime}$ & 4082 & 232.2 & -3.13 \\
\hline 9 & Gozha Co & $34^{\circ} 58^{\prime}-35^{\circ} 05^{\prime}$ & $80^{\circ} 55^{\prime}-81^{\circ} 15^{\prime}$ & 5080 & 252.6 & 1.21 \\
\hline 10 & Zhaling Lake & $34^{\circ} 48^{\prime}-35^{\circ} 01^{\prime}$ & $97^{\circ} 02^{\prime}-97^{\circ} 30^{\prime}$ & 4292 & 526 & -3.13 \\
\hline 11 & Ngoring Lake & $34^{\circ} 45^{\prime}-35^{\circ} 05^{\prime}$ & $97^{\circ} 31^{\prime}-97^{\circ} 55^{\prime}$ & 4269 & 610.7 & -3.13 \\
\hline 12 & Ulan Ul Lake & $34^{\circ} 41^{\prime}-34^{\circ} 55^{\prime}$ & $90^{\circ} 14^{\prime}-90^{\circ} 44^{\prime}$ & 4854 & 544.5 & -3.54 \\
\hline 13 & Dogai Coring & $34^{\circ} 29^{\prime}-34^{\circ} 41^{\prime}$ & $88^{\circ} 32^{\prime}-89^{\circ} 14^{\prime}$ & 4814 & 393.3 & -2.25 \\
\hline 14 & Lumajangdong Co & $33^{\circ} 54^{\prime}-34^{\circ} 07^{\prime}$ & $81^{\circ} 27^{\prime}-81^{\circ} 49^{\prime}$ & 4810 & 324.8 & 1.21 \\
\hline 15 & Pangong Tso & $33^{\circ} 26^{\prime}-33^{\circ} 58^{\prime}$ & $78^{\circ} 25^{\prime}-79^{\circ} 56^{\prime}$ & 4241 & 604 & 1.21 \\
\hline 16 & Chibzhang Co & $33^{\circ} 18^{\prime}-33^{\circ} 40^{\prime}$ & $89^{\circ} 59^{\prime}-90^{\circ} 25^{\prime}$ & 4931 & 476.8 & -2.25 \\
\hline 17 & Dorsoidong Co & $33^{\circ} 16^{\prime}-33^{\circ} 31^{\prime}$ & $89^{\circ} 38^{\prime}-89^{\circ} 59^{\prime}$ & 4921 & 400 & -2.25 \\
\hline 18 & Dagze Lake & $31^{\circ} 49^{\prime}-31^{\circ} 59^{\prime}$ & $87^{\circ} 25^{\prime}-87^{\circ} 39^{\prime}$ & 4459 & 244.7 & 0.46 \\
\hline 19 & Siling Lake & $31^{\circ} 34^{\prime}-31^{\circ} 57^{\prime}$ & $88^{\circ} 33^{\prime}-89^{\circ} 21^{\prime}$ & 4530 & 1628 & 0.46 \\
\hline 20 & Urru Lake & $31^{\circ} 37^{\prime}-31^{\circ} 48^{\prime}$ & $87^{\circ} 50^{\prime}-88^{\circ} 11^{\prime}$ & 4548 & 342.7 & 0.46 \\
\hline 21 & Tso Ngon & $31^{\circ} 25^{\prime}-31^{\circ} 42^{\prime}$ & $88^{\circ} 32^{\prime}-88^{\circ} 50^{\prime}$ & 4561 & 269 & 0.46 \\
\hline 22 & Ang Laren & $31^{\circ} 27^{\prime}-31^{\circ} 40^{\prime}$ & $82^{\circ} 48^{\prime}-83^{\circ} 23^{\prime}$ & 4715 & 512.7 & 0.59 \\
\hline 23 & Gyaring Co & $30^{\circ} 57^{\prime}-31^{\circ} 19^{\prime}$ & $88^{\circ} 03^{\prime}-88^{\circ} 34^{\prime}$ & 4650 & 475.9 & 0.46 \\
\hline 24 & Tangra Yumco & $30^{\circ} 45^{\prime}-31^{\circ} 22^{\prime}$ & $86^{\circ} 23^{\prime}-86^{\circ} 49^{\prime}$ & 4528 & 835.3 & 0.46 \\
\hline 25 & Ngangze Co & $30^{\circ} 54^{\prime}-31^{\circ} 09^{\prime}$ & $86^{\circ} 59^{\prime}-87^{\circ} 20^{\prime}$ & 4683 & 461.5 & 0.46 \\
\hline 26 & Zhari Namco & $30^{\circ} 44^{\prime}-31^{\circ} 05^{\prime}$ & $85^{\circ} 20^{\prime}-85^{\circ} 54^{\prime}$ & 4613 & 996.9 & 0.59 \\
\hline 27 & Nam Co & $30^{\circ} 30^{\prime}-30^{\circ} 56^{\prime}$ & $90^{\circ} 16^{\prime}-91^{\circ} 03^{\prime}$ & 4718 & 1961.5 & 2.20 \\
\hline 28 & Lake Rakshastal & $30^{\circ} 40^{\prime}-30^{\circ} 51^{\prime}$ & $81^{\circ} 06^{\prime}-81^{\circ} 19^{\prime}$ & 4572 & 268.5 & 3.97 \\
\hline 29 & Lake Manasarovar & $30^{\circ} 34^{\prime}-30^{\circ} 47^{\prime}$ & $81^{\circ} 22^{\prime}-81^{\circ} 27^{\prime}$ & 4586 & 412 & 3.97 \\
\hline 30 & Xuru Co & $30^{\circ} 10^{\prime}-30^{\circ} 23^{\prime}$ & $86^{\circ} 20^{\prime}-86^{\circ} 29^{\prime}$ & 4714 & 211.1 & 10.16 \\
\hline 31 & Lake Paiku & $28^{\circ} 46^{\prime}-29^{\circ} 02^{\prime}$ & $85^{\circ} 30^{\prime}-85^{\circ} 42^{\prime}$ & 4580 & 284.4 & 3.93 \\
\hline 32 & Puma Yumco & $28^{\circ} 30^{\prime}-28^{\circ} 38^{\prime}$ & $90^{\circ} 13^{\prime}-90^{\circ} 33^{\prime}$ & 5010 & 290 & 3.27 \\
\hline
\end{tabular}

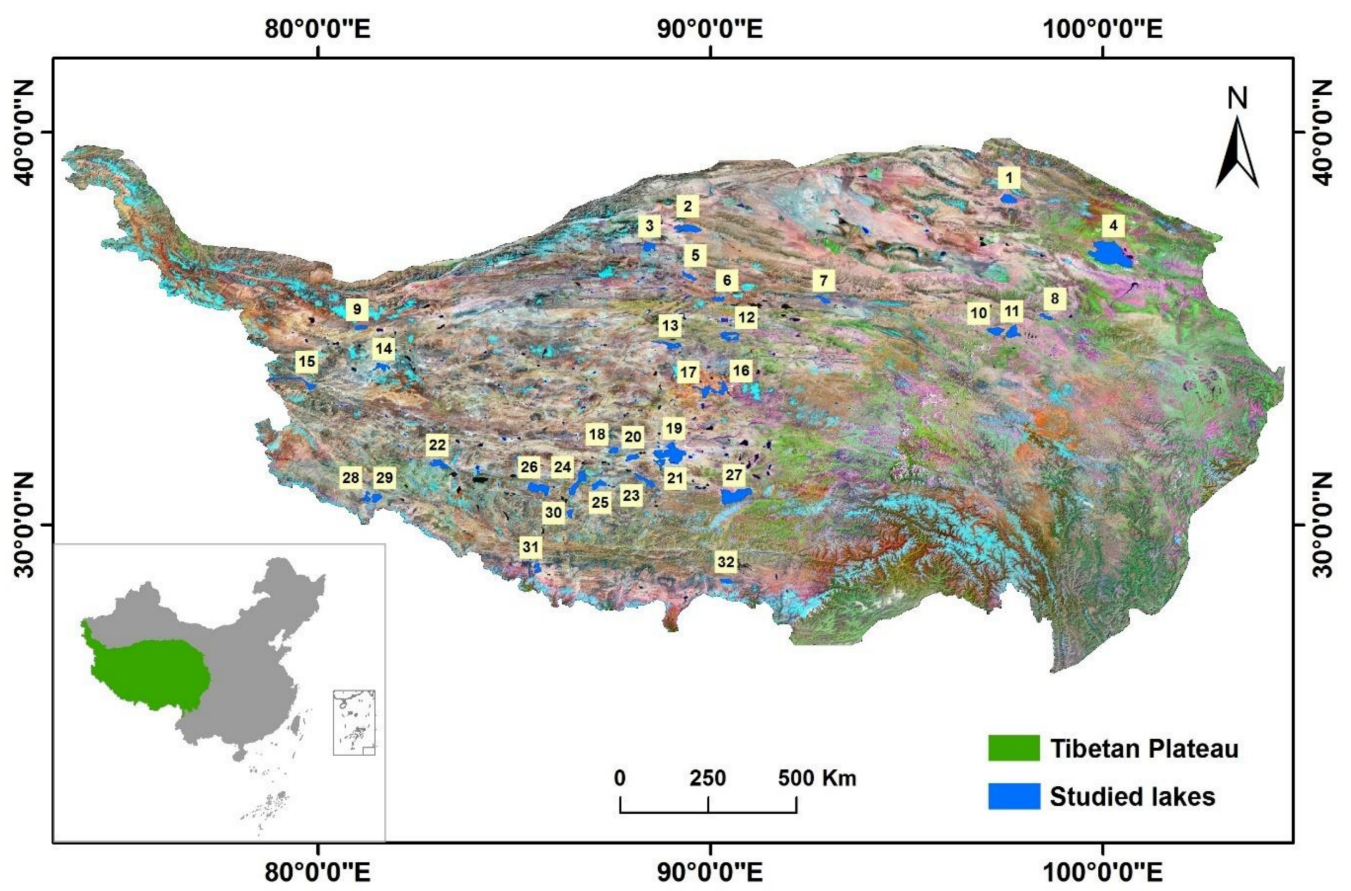

Figure 1. Locations of selected lakes in the Tibetan Plateau (numbered in order of latitude). 


\subsection{Data}

In this research, three remotely sensed datasets (MOD09, MYD10A2, and MOD11A1) from moderate resolution imaging spectroradiometer (MODIS) are used independently to determine the lake ice phenology. MODIS is operated by two polar orbiting satellites, Terra and Aqua. Terra passes from north to south across the equator in the morning, while Aqua passes in the afternoon. They can provide data for the entire earth surface every one to two days with 36 spectral bands, and contain a variety of products that can be applied to different research fields.

The MOD09 is a seven-band product computed from bands 1-7 of MODIS L1B data. The data used for lake ice phenology extraction in this paper are based on the second band (i.e., the near-infrared band) of the MOD09GA product [36], which are daily L2G global $500 \mathrm{~m}$ products. The MODIS snow product (MOD10A2) [37] is an eight-day composite product with a spatial resolution of $500 \mathrm{~m}$ developed by NASA using a unified algorithm. The MOD11A1 [38] used herein consists of L3 surface temperature data with spatial resolution of $1 \mathrm{~km}$.

The meteorological data used were obtained from the China Meteorological Forcing Dataset (CMFD), a near-surface meteorological and environmental reanalysis dataset developed by the Institute of Tibetan Plateau Research, Chinese Academy of Science [39]. The horizontal spatial resolution of CMFD is $0.1^{\circ}$, and the temporal resolution is $3 \mathrm{~h}$.

\section{Methods}

Based on different MODIS data, in this study, three methods are applied to investigate the ice phenology of 32 lakes across the TP. The phases of ice phenology considered herein include freezing-up start (FUS), freezing-up end (FUE), breaking-up start (BUS), and breaking-up end (BUE). The ice-cover duration (ID) and the complete ice-cover duration (CID) are also calculated, which are defined as the difference between FUS and BUE, and the difference between FUE and BUS, respectively.

\subsection{Ice Phenology Determination Based on Reflectance Temporal Profile (M1)}

The idea underlying the determination of lake ice phenology on the basis of the reflectance temporal profile in the NIR band was introduced by Latifovic and Pouliot [19], which made use of the difference between the reflectance of ice/snow and water. The most challenging aspect of this approach (M1) is the determination of the reflectance threshold to separate ice/snow from water. In the work by Latifovic and Pouliot (2007), the threshold was set mainly according majorly to lakes in Canada. For the Tibetan Plateau, however, since there is lack of ground observation and substantial difference in lake physical properties (e.g., depth, shape, and salinity), it is difficult to find an identical reflectance threshold for all lakes to obtain ice phenology from the temporal profile. To determine the threshold for each lake, in this study, 10 cloudless images with coexisting ice and water are selected for $K$-means clustering to obtain the mean clustering center of water and ice/snow. The mean values of the clustering centers $r_{\text {water }}, r_{i c e}$ were then considered as the thresholds of the open and frozen lakes. Meanwhile, the range of thresholds $r_{\min i}-r_{\max }, r_{\min w}-r_{\max w}$ were also obtained from the 10 images.

For the purpose of retrieving lake ice phenology time series, the cloud in the images was firstly removed using the quality control layer in MOD09 data. However, the images excessively affected by cloud cover were excluded. The temporal profile of the mean reflectance of the lake surface was then calculated. Due to the varying atmospheric conditions during acquisition, the presence of cloud shadows, the viewing geometry, and the lower elevation of the sun in the northern winter $[19,40]$, the reflectance time series showing high variability were de-noised and interpolated linearly. The temporal profile was further processed to obtain the upper and lower bounds, which were used to retrieve the FUE and BUS (from the upper bound), and the FUS and BUE (from the lower bound). The purpose of the processing is to reduce the influence of dark artefacts (e.g., shadows) and light artefacts (e.g., cloud and haze) on the upper and lower bounds [19]. 
Intersections of $r_{\text {water }}$ and the lower bound are the initial positions of the FUS/BUE, while the intersections of $r_{i c e}$ and the upper bound are the initial positions of FUE/BUS. In order to obtain the phenology dates, three criteria are set according to the indices $V_{1}, V_{2}$, and $R_{i}$ (Table 2). $R_{i}$ represents the reflectance at position $i$, and

$$
\begin{gathered}
V_{1}=\frac{1}{2 n+1} \sum_{i=i-n}^{i=i+n} D_{i}, \\
V_{2}=M_{1} / M_{2},
\end{gathered}
$$

where

$$
D_{i}=\left\{\begin{array}{l}
1 R_{i}<r_{\text {mean }} \\
0 R_{i}>r_{\text {mean }}
\end{array}, r_{\text {mean }}=\left\{\begin{array}{c}
r_{w a t e r} \text { for FUE/BUS } \\
r_{i c e} \text { for FUS/BUE }
\end{array}\right.\right.
$$

and

$$
M_{1}=\frac{1}{V_{1}(2 n+1)} \sum_{i=i-n}^{i=i+n} R_{i} D_{i} ; M_{2}=\frac{1}{2 n+1} \sum_{j=i+10-n}^{j=i+10+n} R_{j}
$$

Table 2. Criteria of phenology determination based on reflectance temporal profile.

\begin{tabular}{cccc}
\hline Phenology & Criteria A & Criteria B & Criteria C \\
\hline FUS & $V_{1} \leq 0.3$ & $V_{2} \geq 0.4$ & $r_{\text {min }}<R_{i}<r_{\text {max }} . r_{\text {min }}=r_{\text {minw }}, r_{\text {max }}=r_{\text {maxw }}$ \\
FUE & $V_{1} \leq 0.3$ & $V_{2} \leq 0.4$ & $r_{\text {min }}<R_{i}<r_{\text {max }} . r_{\text {min }}=r_{\text {mini }}, r_{\text {max }}=r_{\text {maxi }}$ \\
BUS & $V_{1} \geq 0.7$ & $V_{2} \geq 1.4$ & $r_{\text {min }}<R_{i}<r_{\text {max }} . r_{\text {min }}=r_{\text {mini }}, r_{\text {max }}=r_{\text {maxi }}$ \\
BUE & $V_{1} \geq 0.7$ & $V_{2} \leq 1.4$ & $r_{\text {min }}<R_{i}<r_{\text {max }} . r_{\text {min }}=r_{\text {minw }}, r_{\text {max }}=r_{\text {maxw }}$ \\
\hline
\end{tabular}

Note: FUS, FUE, BUS, and BUE are freezing-up start, freezing-up end, breaking-up start, and breaking-up end, respectively. According to Latifovic et al. [19] and Weber et al. [41], the first condition, $V_{1}$, is the percentage of values below $r_{\text {mean }}$ in the sample window $(i-n, i+n)$. This means that in a window size of $2 n+1$ days, if more than $70 \%$ of the values are below (above) $r_{m e a n}$, the lake is identified as open (frozen). $V_{2}$ is used to determine whether the reflectance after time $i$ exhibited a trend of abrupt change. The third criterion is to determine whether the reflectance $R_{i}$ is in the range of $r_{\min }-r_{\max }$

\subsection{Ice Phenology Determination Based on MODIS Snow Product (M2)}

The approach (M2) based on MODIS snow product refers to that proposed by Kropáček et al. [15] and used by Wang et al. [42]. The principle of the approach is to determine the threshold proportion of the water area to total lake area. In the approach, the total lake area (LA) is considered to be the largest in a given year, and the image with the largest lake area is then used as a mask. Basing on the MOD10 data, we obtained the water area (WA) to calculate the ratio $K(=W A / L A)$ for each image in the year, and to determine the lake ice phenology dates according to following expression:

$$
\left\{\begin{array}{l}
F U S=\operatorname{Min}(t), K(t)=0.9 \\
F U E=\operatorname{Min}(t), K(t)=0.1 \\
B U S=\operatorname{Max}(t), K(t)=0.1 \\
B U E=\operatorname{Max}(t), K(t)=0.9
\end{array}\right.
$$

where $t$ represents the day of year. Expression (5) states that the upper and lower thresholds of the water area ratio $K$ are set to 0.9 and 0.1 [42], respectively. Graphically, the four phenology dates can be obtained when we add two horizontal lines $(K=0.1$ and $K=0.9)$ to the $K(t)$ time series curve. The first intersection point of horizontal line with $K=0.1$ and curve $K(t)$ in a specific year is accepted as the FUE, and the last intersection is the BUS. Meanwhile, the FUS and BUE can be determined as the first and last intersection points, respectively, of the horizontal line with $K=0.9$ and curve $K(t)$. 


\subsection{Ice Phenology Determination Based on Reflectance and LST Data (M3)}

The method (M3) based on reflectance and lake surface temperature was introduced by Weber et al. [41] and includes two steps. First, the NIR reflectance time series of the lake is used to extract the frozen and open period by index $V_{1}$ (similar to M1 described in Section 3.1). In the frozen or open period, the 90th (frozen) and 10th (open) percentiles of the LST $l_{\text {frozen }}, l_{\text {open }}$ are calculated and used as thresholds in the LST time series. In the second step, the index $V_{L S T}$ (Equation (6)) from the LST series is used to determine the phenology dates, where $L_{i}$ is the lake surface temperature at position $i$. The criteria of two steps are shown in Table 3.

$$
V_{L S T}=\frac{1}{2 n+1} \sum_{i=i-n}^{i=i+n} D_{i} ; D_{i}=\left\{\begin{array}{l}
1 L_{i}<l_{L S T} \\
0 L_{i}>l_{L S T}
\end{array} ; l_{L S T}=\left\{\begin{array}{c}
l_{\text {frozen }} \text { for FUE/BUS } \\
l_{\text {open }} \text { for FUS/BUE }
\end{array}\right.\right.
$$

Table 3. Two-step criteria of phenology determination based on land surface temperature (LST) data.

\begin{tabular}{ccc}
\hline Phenology & Criteria Based on NIR & Criteria Based on LST \\
\hline FUS & $V_{1} \leq 0.3, R_{i} \geq r_{\text {water }}$ & $V_{L S T} \geq 0.7, L_{i} \leq l_{\text {open }}$ \\
FUE & $V_{1} \leq 0.3, R_{i} \geq r_{\text {ice }}$ & $V_{L S T} \geq 0.7, L_{i} \leq l_{\text {frozen }}$ \\
BUS & $V_{1} \geq 0.7, R_{i} \leq r_{\text {ice }}$ & $V_{L S T} \leq 0.3, L_{i} \geq l_{\text {frozen }}$ \\
BUE & $V_{1} \geq 0.7, R_{i} \leq r_{\text {water }}$ & $V_{L S T} \leq 0.3, L_{i} \geq l_{\text {open }}$ \\
\hline
\end{tabular}

\subsection{Uncertainty Assessment}

To assess the uncertainty of lake ice phenology determined by the three methods, the triple collocation (TC) approach was applied. The TC method was proposed by Stoffelen (1998) to calibrate scatterometer-derived ocean winds [43], and was subsequently used for error estimation in other fields [44-48]. The advantage of the TC method is that it can assess the uncertainty of data by cross-validating any three linear transformed datasets without knowing the true value and calculate the root mean squared error (RMSE). According to the approach, we can assume a linear relationship to exist between the phenology dates $\left(P_{x}, P_{y}, P_{z}\right)$ derived from the three methods mentioned above and the hypothetical true phenology $P$, expressed as

$$
\begin{aligned}
& P_{x}=a_{x}+b_{x} P+e_{x}, \\
& P_{y}=a_{y}+b_{y} P+e_{y}, \\
& P_{z}=a_{z}+b_{z} P+e_{z},
\end{aligned}
$$

where $e_{x}, e_{y}$, and $e_{z}$ are the residual errors of $P_{x}, P_{y}$, and $P_{z}$, respectively. To eliminate the calibration coefficients, new variables $P_{x}^{*}=P_{x} / b_{x}-a_{x} / b_{x}, e_{x}^{*}=e_{x} / b_{x}$ are introduced, and Equation (7) can be re-written as

$$
\begin{aligned}
& P_{x}^{*}=P+e_{x}^{*} \\
& P_{y}^{*}=P+e_{y}^{*} \\
& P_{z}^{*}=P+e_{z}^{*} .
\end{aligned}
$$

The unknown $P$ can then be eliminated by subtracting the equations in Equation (8) pairwise, which gives

$$
\begin{aligned}
& P_{x}^{*}-P_{y}^{*}=e_{x}^{*}-e_{y}^{*}, \\
& P_{x}^{*}-P_{z}^{*}=e_{x}^{*}-e_{z}^{*}, \\
& P_{y}^{*}-P_{z}^{*}=e_{y}^{*}-e_{z}^{*} .
\end{aligned}
$$


As the errors are independent, i.e., $\left\langle e_{x}^{*} e_{y}^{*}\right\rangle=\left\langle e_{x}^{*} e_{z}^{*}\right\rangle=\left\langle e_{y}^{*} e_{z}^{*}\right\rangle=0$. By the pairwise multiplication of the lines in Equation (9) and averaging, the mean square errors independent of the true value are obtained:

$$
\begin{aligned}
& \left\langle\left(e_{x}^{*}\right)^{2}\right\rangle=\left\langle\left(P_{x}^{*}-P_{y}^{*}\right)\left(P_{x}^{*}-P_{z}^{*}\right)\right\rangle, \\
& \left\langle\left(e_{y}^{*}\right)^{2}\right\rangle=\left\langle\left(P_{y}^{*}-P_{x}^{*}\right)\left(P_{y}^{*}-P_{z}^{*}\right)\right\rangle, \\
& \left\langle\left(e_{z}^{*}\right)^{2}\right\rangle=\left\langle\left(P_{z}^{*}-P_{x}^{*}\right)\left(P_{z}^{*}-P_{y}^{*}\right)\right\rangle .
\end{aligned}
$$

As the truth is unknown, we select $P_{x}$ as the reference data and set $a_{x}=0, b_{x}=1$. This choice does not affect the estimated errors because of the symmetry of Equation (9). The coefficients $a_{y}, b_{y}$ and $a_{z}, b_{z}$ can then be calculated using a simple linear least-squares approximation that considers errors in both variables [49]. An iteration scheme has to be invoked to calculate $\left\langle e_{x}^{*}\right\rangle^{2},\left\langle e_{y}^{*}\right\rangle^{2},\left\langle e_{z}^{*}\right\rangle^{2}$ because the calibration of the $P_{y}$ and $P_{z}$ constants will affect the estimation of errors in $P_{x}, P_{y}$, and $P_{z}$. In this study, we start the estimation with the initial guess of the calibration parameters by assuming $\left\langle\left(e_{x}\right)^{2}\right\rangle=\left\langle\left(e_{y}\right)^{2}\right\rangle=\left\langle\left(e_{z}\right)^{2}\right\rangle$ and subsequently solving the calibration and error equations until the iteration procedure is convergent. The $e_{x}, e_{y}$, and $e_{z}$ are eventually obtained as linear transformations of $e_{x}^{*}, e_{y}^{*}$, and $e_{z}^{*}$, respectively.

\section{Results and Discussions}

\subsection{Consistency and Uncertainty of Lake Ice Phenology from Different Approaches}

Figure 2 shows the annual mean ice phenology of each lake obtained by the three approaches, where M1, M2, and M3 respectively represent the approaches described in Sections 3.1-3.3. The abscissa denotes the day of year of the phenology, in which the number larger than 365 indicates dates in the consecutive year. As shown in Figure 2, the three approaches consistently show that the lake ice phenology varies substantially among the lakes. In general, the freezing-up starts (FUS) from mid-November to early January, while the freezing-up ending (FUE) varies from early December to early February. The breaking-up starts (BUS) from mid-Match to mid-May, while the BUE lasts from mid-April to late June. Figure 2 also shows the difference among the three approaches. For most lakes, the four phenology dates determined by M1 are larger (later) than those obtained through the other two approaches. The FUS and FUE derived via M3 are often smaller (earlier) than those derived via M1 and M2. Moreover, for lakes with shorter ice-cover duration (e.g., Tangra Yumco, Xuru Co, and Pangong Tso), the CID and ID calculated based on M3 are longer than those from M1 and M2.

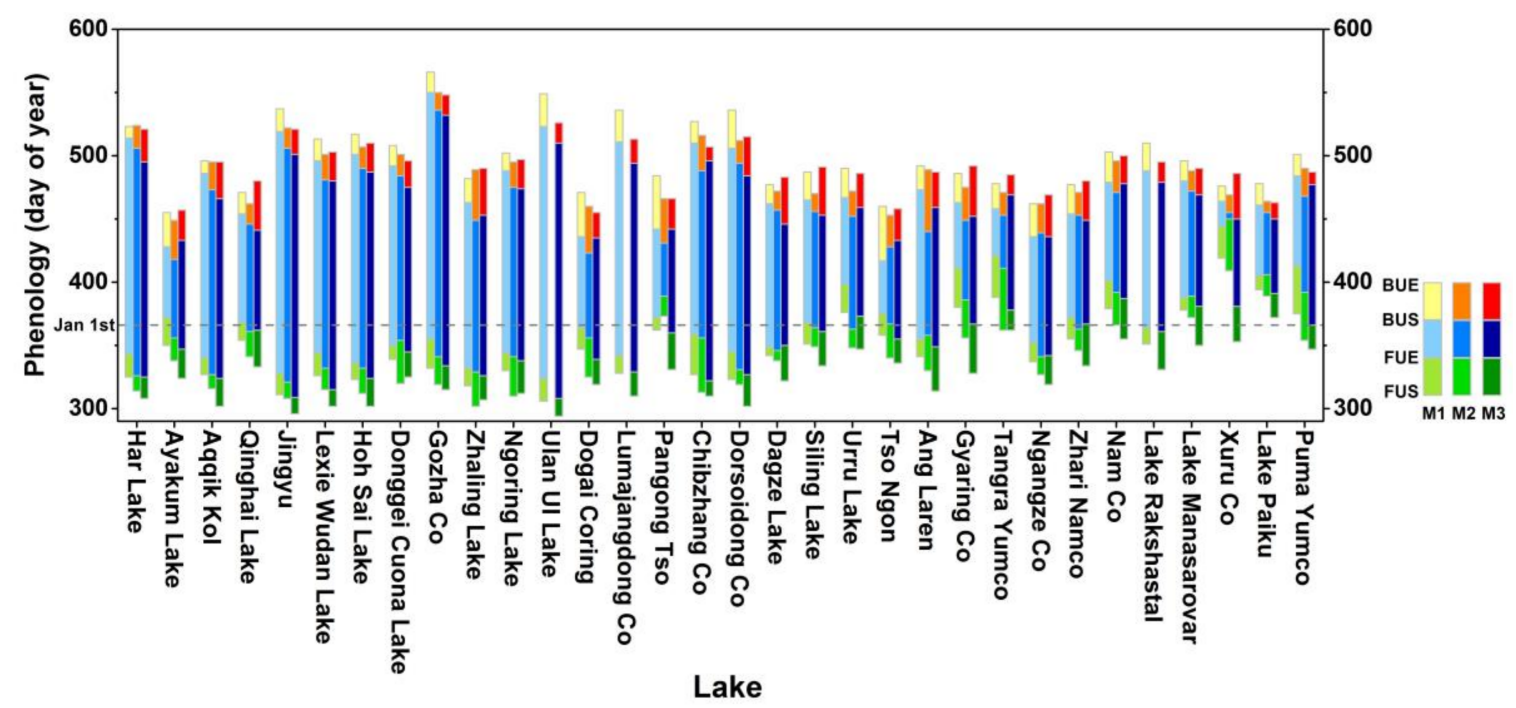

Figure 2. Dates of ice phenology of the studied lakes. (Lakes were sorted by latitude. M1, M2, and M3 respectively represent the methods described in Sections 3.1-3.3). 
The consistency of lake ice phenology for all lakes using different approaches was further investigated by correlation analysis with respect to phenology dates for all lakes in the period 2000-2015 (sample size $=32 \times 16$ ). As shown in Table 4, it was found that the pair correlation coefficients of the BUS and BUE are higher than those of FUS and FUE, indicating that the methods are in better agreement on determining the breaking-up rather than the freezing-up phase. In general, for all lakes, the three methods record better agreement on monitoring the BUS, BUE, and ID. Agreement of the phenology dates derived was found to be higher between M1 and M2, but lower between M2 and M3. Though the results indicate that M1 and M2 are more consistent with each other, it is difficult to determine which approach is more appropriate owing to the lack of ground observations.

Table 4. Correlation $\left(\mathrm{R}^{2}\right)$ between lake ice phenology indices from different approaches.

\begin{tabular}{cccc}
\hline Phenology & M1 and M2 & M1 and M3 & M2 and M3 \\
\hline FUS & 0.72 & 0.77 & 0.65 \\
FUE & 0.67 & 0.54 & 0.59 \\
BUS & 0.85 & 0.78 & 0.74 \\
BUE & 0.85 & 0.76 & 0.75 \\
CID & 0.86 & 0.73 & 0.69 \\
ID & 0.83 & 0.77 & 0.73 \\
\hline
\end{tabular}

Note: CID and ID represent the complete ice-cover duration and ice-cover duration

Without the "true" observation of lake ice phenology, the uncertainty of the results from the three methods can nevertheless be assessed by the TC methods applied to the phenology time series for all lakes in the period of 2000-2015 (sample size $=32$ lakes $\times 16$ years). As shown in Table 5, M1 outperforms the other two methods by showing advantages (with smaller a RMSE) in determining the FUS, FUE, BUE, and ID, but a slight weakness in the BUS. M2 records the lowest uncertainty in CID $($ RMSE $=15.5$ days), but with the highest uncertainty in ID (RMSE $=37.4$ days).

Table 5. Uncertainty of derived lake ice phenology dates assessed by triple collocation approach (RMSE in days).

\begin{tabular}{cccc}
\hline Phenology & M1 & M2 & M3 \\
\hline FUS & 4.1 & 17.0 & 11.0 \\
FUE & 11.3 & 14.1 & 15.9 \\
BUS & 13.4 & 10.7 & 10.4 \\
BUE & 4.7 & 16.7 & 12.7 \\
CID & 17.8 & 15.5 & 21.1 \\
ID & 12.2 & 37.4 & 20.8 \\
\hline
\end{tabular}

It is worth noting that the spatial resolution of the data used in M1 and M2 is $500 \mathrm{~m}$, but it is $1 \mathrm{~km}$ for M3. Meanwhile, the temporal resolutions of the remotely sensed data used in M1 and M3 are both daily, but it is eight days in M2. The difference in the temporal-spatial resolution could contribute to the different uncertainties of the derived lake ice phenology. To reduce the uncertainties, remotely sensed data with a higher spatial and temporal resolution would be valuable. Moreover, it should be noted that M1 is not limited to MODIS data, but is also applicable to other data sources such as AVHRR and medium resolution imaging spectrometer (MERIS). On the contrary, M2 relies only on MODIS snow products.

\subsection{Spatial Variation of Lake Ice Phenology in Relation to Climate}

The ice phenology of lakes in the Tibetan Plateau varies substantially across the plateau. For the freezing-up phase, the lakes with earlier dates (smaller FUS and FUE) are located in at the north of the TP (including Har Lake, Aqqik Kol, Jingyu, Lexie Wudan Lake, and Hoh Sai Lake), while the lakes with later dates (higher FUS and FUE) are located in the south of the TP (including Puma Yumco, Lake 
Paiku, Xuru Co, and Lake Manasarovar). The maximum difference of the FUS or FUE among the lakes could reach up to 84 days. For the breaking-up, the lakes in the south of the TP tend to be earlier (smaller BUS and BUE) than those in the northern part of the TP; the difference in the breaking-up date could reach up to 114 days. The differences in the freezing-up and breaking-up dates resulted in the ice-cover duration (CID) of the lakes ranging from 55 days (Xuru Co) to 200 days (Ulan Ul Lake). Generally the CID and ID in the northern part of the TP was longer than in the south.

The spatial variation of lake ice phenology is highly related to the regional climate condition $[19,20]$. To show the effect of climate on spatial variation of lake ice phenology, in this paper, the correlation between phenology dates and climate variables (i.e., lake surface temperature, wind speed, air pressure, and precipitation) was investigated. The lake surface temperature is the mean temperature of the period from December to May obtained from the MODIS LST product, while wind speed, air pressure, and precipitation were obtained from CMFD. As illustrated in Figure 3, for all six phenology indices, FUS and FUE show positive correlations with temperature, but the other indices show negative correlations with temperature. The results indicate that a higher temperature is accompanied with later freezing-up, earlier breaking-up, and shorter ice-cover duration. Since the temperature decreases with the increase of latitude and altitude, the ice phenology of lakes in the northern TP (higher latitude) tends to experience earlier freezing-up and later breaking-up. It was also found that the freezing-up phase has a closer correlation with temperature than the breaking-up as indicated by the correlation coefficients in Figure 3.

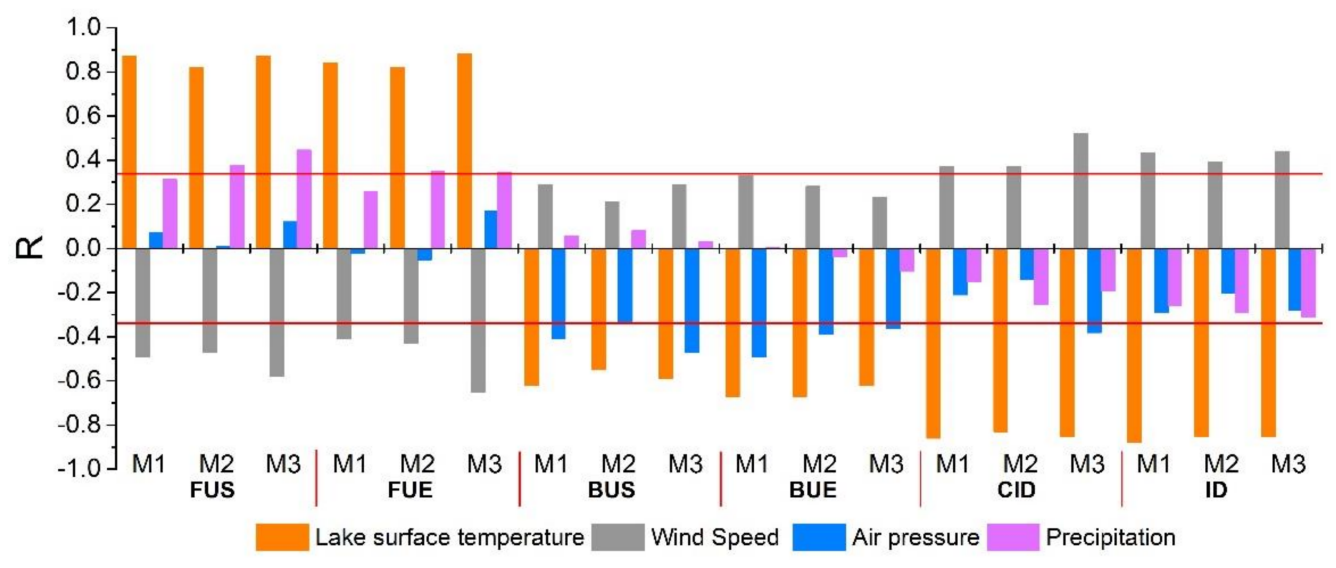

Figure 3. Spatial correlation between lake ice phenology and environmental factors (M1, M2, and M3 respectively represent the methods described in Sections 3.1-3.3; red line represents the correlation coefficient corresponding to $p=0.05$ ). The lake surface temperature is the mean of temperature of the period from December to May obtained from the MODIS LST product; wind speed, air pressure, and precipitation data were obtained from CMFD.

Wind speed is another factor affecting the formation or breaking of lake ice. As shown in Figure 3, across the TP, the FUS and FUE have negative correlations with wind speed in winter (mean of November to December), while the BUS and BUE have positive correlations with wind speed in spring (mean of April to May). In addition, CID/ID also correlate positively with wind speed (mean of November to May). The results indicate that the stronger the wind speed, the earlier the freezing-up starts and the later the breaking-up ends. This could be because the wind accelerates convection on the lake surface and bring cold air on the top of the lake, thus accelerating the freezing processes and postponing the thawing of ice. However, strong wind could destroy weak or thin ice, thus extending the freezing-up duration of the lake [50,51]. Air pressure was also found to be negatively correlated to the BUS and BUE, which is partly because the lower the air pressure, the higher the freezing point of water. Precipitation was correlated positively with the FUS and FUE, but not significantly correlative to the breaking-up process. This could be because rainfall/snowfall in the ice season not only lowers 
the air temperature, but the gravity of rain also destroys the formation of lake ice [52], thus postponing the freezing-up process.

It is worth pointing out that the lake ice phenology is not only affected by climate conditions, but could also be influenced by other physical or chemical properties of the lake. For example, the thermal capacity of the lake water depends on the depth and area of the lake. Moreover, the salinity of water could change the freezing point of the lake, thus affecting the formation and ablation of lake ice.

\subsection{Interannual Variation of Lake Ice Phenology in Relation to Climate}

To investigate the interannual variation of lake ice phenology, a trend analysis was conducted with the application of the Mann-Kendall (MK) test [53,54]. The MK test is a non-parametric test widely used to detect the trend of hydroclimate variables [55,56]. Figure 4 shows the ice phenology trend of 24 lakes for the period of 2000 to 2015 obtained from the three methods, where the other eight lakes are absent due to having a large proportion of missing data. As seen from the figure, M1 and M2 generally show quite similar trends of lake phenology in most cases. The results from M3 are largely similar to those of M1 and M2, except for those lakes (e.g., Ayakum Lake, Lexie Wudan Lake, Dogai Coring) with significant decreasing trends detected by M1 and M2.

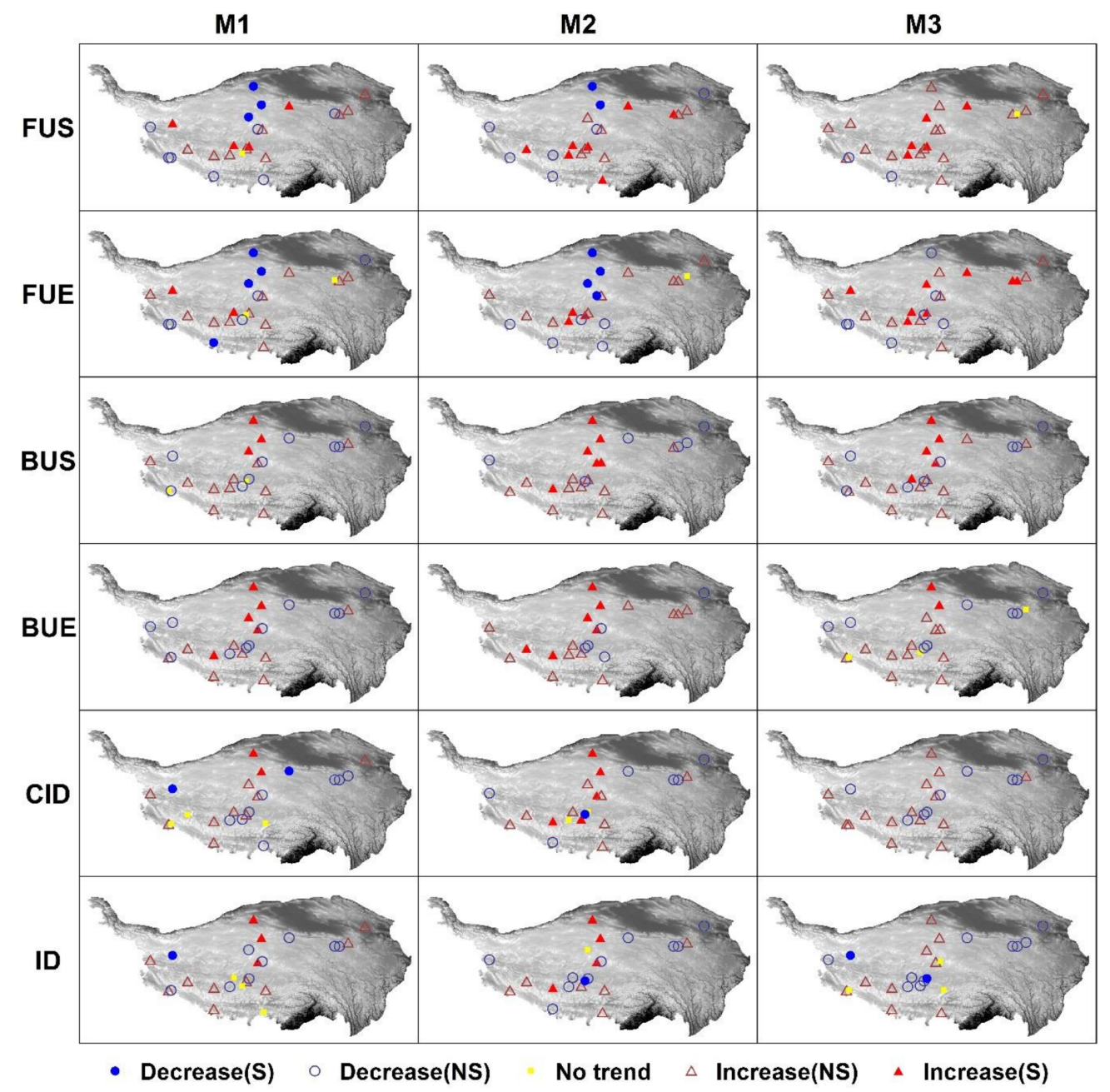

Figure 4. Trend of variation in lake ice phenology and duration of ice cover from Mann-Kendall test. Blue circle means earlier FUS/FUE/BUS/BUE and shortening CID/ID; red triangle means later FUS/FUE/BUS/BUE and extended CID/ID. Solid circle or triangle means the trend is statistically significant and the confidence level is $95 \%$, while hollow circle or triangle means no significant trend. Yellow squares represent no trend. 
It can be seen in Figure 4 that there is no general trend of lake ice phenology across the Tibetan Plateau. According to the results from M1, 13 lakes showed increasing trends in both FUS and FUE, indicating the delayed freezing-up of lake ice. However, the trend was only of statistical significance for FUS in four lakes, and for FUE in two lakes. Meanwhile, seven lakes showed decreasing trends in both FUS and FUE, but two lakes (Qinghai Lake and Tso Ngon) show later FUS and earlier FUE. A contrary tendency of both BUS and BUE was found for most lakes, which means lakes with later (earlier) FUS and FUE tend to have earlier (later) BUS and BUE. As a result of changes in the freezing-up and breaking-up dates of lake ice, the ice-cover duration was found to become longer in 11 (or 12) lakes for CID (or ID), while nine lakes showed shorter duration. Different trends between FUS and FUE (or between BUS and BUE) were seen in some lakes (e.g., Pangong Tso, Gyaring Co, Ngangze Co, Pumayumco), implying that climate conditions in the period between FUS and FUE (or between BUS and BUE) contribute critically to the phenology shifts.

The different trends of lake ice phenology across the TP imply that the underlying causes (e.g., changes in climate or other environmental factors) vary substantially across the region. Among all of the environmental factors, climate factors have played a dominant role in the shifting of lake ice phenology. As shown in Figure 5, depicting the temporal correlation between climate factors and the phenology indices for each lake, the FUS and FUE were found to be positively related to temperature for most lakes, which means that the warmer climate had led to the later freezing-up of lake ice. Meanwhile, the BUS, BUE, CID, and ID were negatively correlated with temperature, implying that the warmer climate had resulted in the earlier breaking-up of lake ice and a shortened ice covering duration. In some lakes (e.g., Ayakum Lake), the BUS and BUE were highly negatively related to radiation or wind speed, which suggests that the higher the radiation or the stronger the wind, the earlier the breaking-up of lake ice. Similarly to temperature, air pressure also showed a positive correlation with the FUS and FUE, but a negative correlation with the BUS, BUE, CID, and ID, that is, because the freezing point is inversely related to air pressure. Temporally, precipitation tended to show positive relations with the lake ice phenology for most lakes, meaning that the higher (lower) the precipitation, the later (earlier) the freezing-up and breaking-up of lake ice. This could be because the increase (decrease) of precipitation leads to more (less) water storage of the lakes and, hence, changes the thermal capacity of the lakes. 


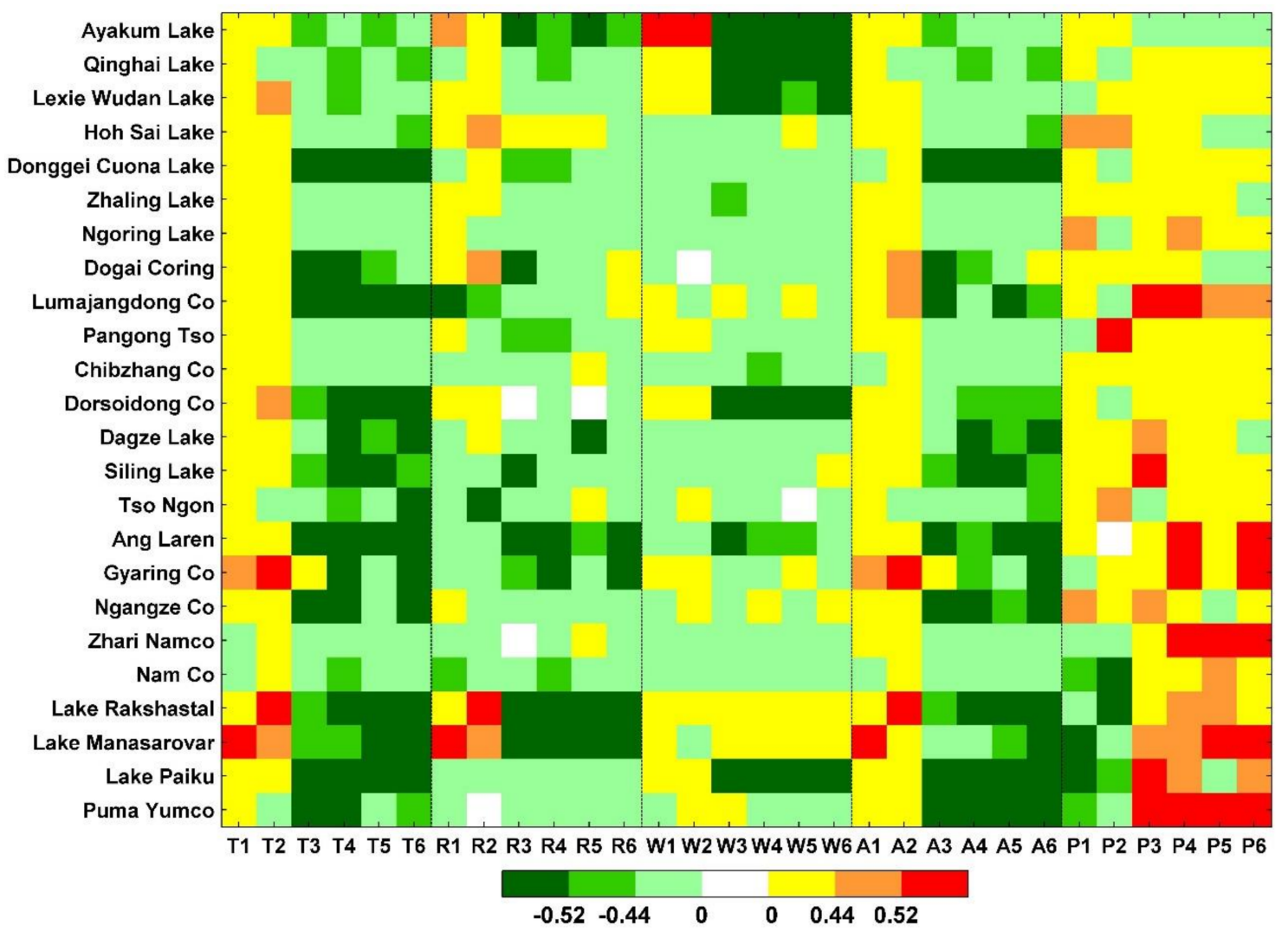

Figure 5. Heatmap of correlation coefficients between lake ice phenology indices and climate factors. $\mathrm{T}, \mathrm{R}, \mathrm{W}, \mathrm{A}$, and $\mathrm{P}$ represent temperature, radiation, wind speed, air pressure, and precipitation, respectively. The FUS, FUE, BUS, BUE, CID and ID are notated by $1-6$, respectively. For example, T1 represents the correlation between temperature and FUS.

\section{Conclusions}

Lake ice phenology is a sensitive indicator reflecting global warming. In the Tibetan Plateau, the changes of lake ice phenology not only represent regional climate change, but also reveal substantial ecohydrological impacts on the local environment. For the investigation of lake ice phenology in the Tibetan Plateau, the value of remotely sensed data is more notable due to the harsh nature that may prevent the collection of ground observations. However, uncertainties exist in the determination of the phenology owing to both the methods and the remotely sensed data used, which may result in an inconsistent understanding of the variation of lake ice phenology across the TP.

In this research, the uncertainties of three methods based on different remotely sensed data (MODIS reflectance data, snow product, and land surface temperature data) have been assessed using the triple collocation approach. The three methods are more consistent in determining the breaking-up rather than the freezing-up of lake ice phenology. Comparatively, the method based on MODIS reflectance data outperforms the other two by showing smaller uncertainty in determining FUS, FUE, BUE, and ID. The different uncertainties of the methods could partly due to the temporal-spatial resolution of the data used.

Though uncertainties exist, the three methods consistently show that the ice-cover duration in the northern part of the TP used to be longer than that in the south, and the northern TP (higher latitude) experiences earlier freezing-up and later breaking-up of lake ice. The freezing-up dates were found to have a closer correlation with temperature than the breaking-up dates. During the period of 2000-2015, there was no general trend of lake ice phenology across the TP. However, the warmer climate led to the later freezing-up and earlier breaking-up of lake ice across the TP. 
Author Contributions: L.G. and Y.W. contributed equally to this work. Y.W., H.Z., and B.Z. contributed to the original idea and completed the theoretical framework; L.G. was responsible for the methods and processed the data; L.G., Y.W., and H.Z. contributed to the analysis and discussion; L.G. and Y.W. wrote the original draft; H.Z., B.Z., and J.L. revised the paper; F.Z. and Q.S. provided important suggestions for improving the paper.

Funding: This research was funded by the National Key R\&D Program of China (2016YFA0600303), National Natural Science Foundation of China (41671203, 41371218).

Acknowledgments: The China Meteorological Forcing Dataset (CMFD) used in this study was developed by the Data Assimilation and Modeling Center for Tibetan Multi-spheres, Institute of Tibetan Plateau Research of Chinese Academy of Sciences (http:/ / westdc.westgis.ac.cn/). Temperature data of meteorological station was from the China Meteorological Data Service Center (CMDC): http:/ / data.cma.cn/.

Conflicts of Interest: The authors declare no conflict of interest.

\section{References}

1. Liu, X.D.; Chen, B.D. Climatic warming in the Tibetan Plateau during recent decades. Int. J. Climatol. 2000, 20, 1729-1742. [CrossRef]

2. Zhang, B.; Wu, Y.; Lei, L.; Li, J.; Liu, L.; Chen, D.; Wang, J. Monitoring changes of snow cover, lake and vegetation phenology in Nam Co Lake Basin (Tibetan Plateau) using remote SENSING (2000-2009). J. Great Lakes Res. 2013, 39, 224-233. [CrossRef]

3. Alley, R.B.; Meese, D.A.; Shuman, C.A.; Gow, A.J.; Taylor, K.C.; Grootes, P.M.; White, J.W.C.; Ram, M.; Waddington, E.D.; Mayewski, P.A.; et al. Abrupt Increase in Greenland Snow Accumulation at the End of the Younger Dryas Event. Nature 1993, 362, 527-529. [CrossRef]

4. Li, C.L.; Kang, S.C. Review of the studies on climate change since the last inter-glacial period on the Tibetan Plateau. J. Geogr. Sci. 2006, 16, 337-345. [CrossRef]

5. Dornhofer, K.; Oppelt, N. Remote sensing for lake research and monitoring-Recent advances. Ecol. Indic. 2016, 64, 105-122. [CrossRef]

6. Vincent, W.F. Effects of Climate Change on Lakes. In Encyclopedia of Inland Waters; Likens, G.E., Ed.; Elsevier Science Publishing Co. Inc.: Amsterdam, The Netherlands, 2007; pp. 55-60. ISBN 978-0-12-370626-3.

7. Lu, C.X.; Yu, G.; Xie, G.D. Tibetan plateau serves as a water tower. In Proceedings of the 25th IEEE International Geoscience and Remote Sensing Symposium (IGARSS 2005), Seoul, Korea, 25-29 July 2005.

8. Wu, Y.H.; Zheng, H.X.; Zhang, B.; Chen, D.M.; Lei, L.P. Long-Term Changes of Lake Level and Water Budget in the Nam Co Lake Basin, Central Tibetan Plateau. J. Hydrometeorol. 2014, 15, 1312-1322. [CrossRef]

9. Fu, C.S.; Yao, H.X. Trends of ice breakup date in south-central Ontario. J. Geophys. Res. Atmos. 2015, 120, 9220-9236. [CrossRef]

10. Ke, C.Q.; Tao, A.Q.; Jin, X. Variability in the ice phenology of Nam Co Lake in central Tibet from scanning multichannel microwave radiometer and special sensor microwave/imager: 1978 to 2013. J. Appl. Remote Sens. 2013, 7, 12. [CrossRef]

11. Livingstone, D.M. Break-up dates of Alpine lakes as proxy data for local and regional mean surface air temperatures. Clim. Chang. 1997, 37, 407-439. [CrossRef]

12. Kouraev, A.V.; Semovski, S.V.; Shimaraev, M.N.; Mognard, N.M.; Legresy, B.; Remy, F. Observations of Lake Baikal ice from satellite altimetry and radiometry. Remote Sens. Environ. 2007, 108, 240-253. [CrossRef]

13. Marszelewski, W.; Skowron, R. Ice cover as an indicator of winter air temperature changes: Case study of the Polish Lowland lakes. Hydrol. Sci. J.-J. Sci. Hydrol. 2006, 51, 336-349. [CrossRef]

14. Walsh, S.E.; Vavrus, S.J.; Foley, J.A.; Fisher, V.A.; Wynne, R.H.; Lenters, J.D. Global patterns of lake ice phenology and climate: Model simulations and observations. J. Geophys. Res. Atmos. 1998, 103, 28825-28837. [CrossRef]

15. Kropacek, J.; Maussion, F.; Chen, F.; Hoerz, S.; Hochschild, V. Analysis of ice phenology of lakes on the Tibetan Plateau from MODIS data. Cryosphere 2013, 7, 287-301. [CrossRef]

16. Zhang, G.Q.; Xie, H.J.; Kang, S.C.; Yi, D.H.; Ackley, S.F. Monitoring lake level changes on the Tibetan Plateau using ICESat altimetry data (2003-2009). Remote Sens. Environ. 2011, 115, 1733-1742. [CrossRef]

17. Wu, Y.; Zhu, L.; Ye, Q.; Wang, L. The response of lake-glacier area change to climate variations in Namco Basin, Central Tibetan Plateau, during the last three decades. Acta Geogr. Sin. 2007, 62, 301-311. 
18. Benson, B.J.; Magnuson, J.J.; Jensen, O.P.; Card, V.M.; Hodgkins, G.; Korhonen, J.; Livingstone, D.M.; Stewart, K.M.; Weyhenmeyer, G.A.; Granin, N.G. Extreme events, trends, and variability in Northern Hemisphere lake-ice phenology (1855-2005). Clim. Chang. 2012, 112, 299-323. [CrossRef]

19. Latifovic, R.; Pouliot, D. Analysis of climate change impacts on lake ice phenology in Canada using the historical satellite data record. Remote Sens. Environ. 2007, 106, 492-507. [CrossRef]

20. Magnuson, J.J.; Robertson, D.M.; Benson, B.J.; Wynne, R.H.; Livingstone, D.M.; Arai, T.; Assel, R.A.; Barry, R.G.; Card, V.; Kuusisto, E.; et al. Historical trends in lake and river ice cover in the Northern Hemisphere. Science 2000, 289, 1743-1746. [CrossRef] [PubMed]

21. Gou, P.; Ye, Q.; Che, T.; Feng, Q.; Ding, B.; Lin, C.; Zong, J. Lake ice phenology of Nam Co, Central Tibetan Plateau, China, derived from multiple MODIS data products. J. Great Lakes Res. 2017, 43, 989-998. [CrossRef]

22. Brown, L.C.; Duguay, C.R. The response and role of ice cover in lake-climate interactions. Prog. Phys. Geogr. 2010, 34, 671-704. [CrossRef]

23. Bernhardt, J.; Engelhardt, C.; Kirillin, G.; Matschullat, J. Lake ice phenology in Berlin-Brandenburg from 1947-2007: Observations and model hindcasts. Clim. Chang. 2012, 112, 791-817. [CrossRef]

24. Dibike, Y.; Prowse, T.; Saloranta, T.; Ahmed, R. Response of Northern Hemisphere lake-ice cover and lake-water thermal structure patterns to a changing climate. Hydrol. Process. 2011, 25, 2942-2953. [CrossRef]

25. Ghanbari, R.N.; Bravo, H.R.; Magnuson, J.J.; Hyzer, W.G.; Benson, B.J. Coherence between lake ice cover, local climate and teleconnections (Lake Mendota, Wisconsin). J. Hydrol. 2009, 374, 282-293. [CrossRef]

26. Che, T.; Li, X.; Jin, R. Monitoring the frozen duration of Qinghai Lake using satellite passive microwave remote sensing low frequency data. Chin. Sci. Bull. 2009, 54, 787-791. [CrossRef]

27. Kang, K.K.; Duguay, C.R.; Howell, S.E.L. Estimating ice phenology on large northern lakes from AMSR-E: Algorithm development and application to Great Bear Lake and Great Slave Lake, Canada. Cryosphere 2012, 6, 235-254. [CrossRef]

28. Ruan, Y.; Qiu, Y.; Yu, X.; Guo, H.; Cheng, B. Passive microwave remote sensing of lake freeze-thaw over High Mountain Asia. In Proceedings of the 36th IEEE International Geoscience and Remote Sensing Symposium (IGARSS), Beijing, China, 10-15 July 2016; pp. 2818-2821.

29. Cai, Y.; Ke, C.Q.; Duan, Z. Monitoring ice variations in Qinghai Lake from 1979 to 2016 using passive microwave remote sensing data. Sci. Total Environ. 2017, 607-608, 120-131. [CrossRef] [PubMed]

30. Duguay, C.R.; Bernier, M.; Gauthier, Y.; Kouraev, A. Remote sensing of lake and river ice. In Remote Sensing of the Cryosphere, 1st ed.; Tedesco, M., Ed.; Wiley-Blackwell: Hoboken, NJ, USA, 2015; pp. 273-306. ISBN 978-1-118-36885-5.

31. Nonaka, T.; Matsunaga, T.; Hoyano, A. Estimating ice breakup dates on Eurasian lakes using water temperature trends and threshold surface temperatures derived from MODIS data. Int. J. Remote Sens. 2007, 28, 2163-2179. [CrossRef]

32. Wei, Q.; Ye, Q. Review of Lake Ice Monitoring by Remote Sensing. Prog. Geogr. 2010, 29, 803-810.

33. Mao, D.H.; Wang, Z.M.; Yang, H.; Li, H.Y.; Thompson, J.R.; Li, L.; Song, K.S.; Chen, B.; Gao, H.K.; Wu, J.G. Impacts of Climate Change on Tibetan Lakes: Patterns and Processes. Remote Sens. 2018, 10, 358. [CrossRef]

34. Yao, T.; Wu, F.; Lin, D.; Sun, J.; Zhu, L.; Piao, S.; Tao, D.; Ni, X.; Zheng, H.; Hua, O. Multispherical interactions and their effects on the Tibetan Plateau's earth system: A review of the recent researches. Natl. Sci. Rev. 2015, 2, 468-488. [CrossRef]

35. Wang, S.M.; Dou, H.S. Records of Lakes in China, 1st ed.; Science Press: Beijing, China, 1998; pp. $342-483$. ISBN 7-03-006706-1.

36. Vermote, E. MOD09GA Surface Reflectance Daily L2G Global $1 \mathrm{~km}$ and $500 \mathrm{~m}$ SIN Grid V006; NASA EOSDIS Land Processes DAAC; NASA: Washington, DC, USA, 2015.

37. Hall, D.K.; Riggs, G.A. MODIS/Aqua Snow Cover 8-Day L3 Global 500 m Grid, Version 6; NASA National Snow and Ice Data Center Distributed Active Archive Center: Boulder, CO, USA, 2016.

38. Wan, Z. MOD11A1 Land Surface Temperature/Emissivity Daily L3 Global 1 km SIN Grid; NASA EOSDIS Land Processes DAAC: Boulder, CO, USA, 2013.

39. Yang, K.; He, J.; Tang, W.J.; Qin, J.; Cheng, C.C.K. On downward shortwave and longwave radiations over high altitude regions: Observation and modeling in the Tibetan Plateau. Agric. For. Meteorol. 2010, 150, 38-46. [CrossRef]

40. Lang, J.H.; Lyu, S.H.; Li, Z.G.; Ma, Y.M.; Su, D.S. An Investigation of Ice Surface Albedo and Its Influence on the High-Altitude Lakes of the Tibetan Plateau. Remote Sens. 2018, 10, 218. [CrossRef] 
41. Weber, H.; Riffler, M.; Noges, T.; Wunderle, S. Lake ice phenology from AVHRR data for European lakes: An automated two-step extraction method. Remote Sens. Environ. 2016, 174, 329-340. [CrossRef]

42. Wang, Z.; Wu, Y.; Chang, J.; Zhang, X.; Peng, D. Temporal and Spatial Variation of Lake Ice Phenology and Its Influencing Factors in the Tibetan Plateau. J. Beijing Univ. Technol. 2017, 43, 701-709.

43. Stoffelen, A. Toward the true near-surface wind speed: Error modeling and calibration using triple collocation. J. Geophys. Res. Oceans 1998, 103, 7755-7766. [CrossRef]

44. Fang, H.L.; Wei, S.S.; Jiang, C.Y.; Scipal, K. Theoretical Uncertainty Analysis of Global Modis, Cyclopes, and Globcarbon Lai Products Using a Triple Collocation Method. Remote Sens. Environ. 2012, 124, 610-621. [CrossRef]

45. Scipal, K.; Holmes, T.; de Jeu, R.; Naeimi, V.; Wagner, W. A possible solution for the problem of estimating the error structure of global soil moisture data sets. Geophys. Res. Lett. 2008, 35, 4. [CrossRef]

46. Lin, W.M.; Portabella, M.; Stoffelen, A.; Vogelzang, J.; Verhoef, A. ASCAT wind quality under high subcell wind variability conditions. J. Geophys. Res. Oceans 2015, 120, 5804-5819. [CrossRef]

47. Gentemann, C.L. Three way validation of MODIS and AMSR-E sea surface temperatures. J. Geophys. Res. Oceans 2014, 119, 2583-2598. [CrossRef]

48. Janssen, P.; Abdalla, S.; Hersbach, H.; Bidlot, J.R. Error estimation of buoy, satellite, and model wave height data. J. Atmos. Ocean. Technol. 2007, 24, 1665-1677. [CrossRef]

49. York, D.; Evensen, N.M.; MartíNez, M.L.; Delgado, J.D.B. Unified equations for the slope, intercept, and standard errors of the best straight line. Am. J. Phys. 2004, 72, 367-375. [CrossRef]

50. Qu, B.; Kang, S.; Chen, F.; Zhang, Y.; Zhang, G. Lake Ice and Its Effect Factors in the Nam Co Basin, Tibetan Plateau. Prog. Inquis. Mutat. Clim. 2012, 8, 327-333.

51. Shen, H.T. River Ice Processes. In Advances in Water Resources Management; Handbook of Environmental, Engineering; Wang, L.K., Yang, C.T., Wang, M.S., Eds.; Springer: Cham, Germany, 2016; Volume 16, pp. 483-530. ISBN 978-3-319-22923-2.

52. Kolerski, T.; Shen, H.T. Possible effects of the 1984 St. Clair River ice jam on bed changes. Can. J. Civ. Eng. 2015, 42, 696-703. [CrossRef]

53. Kendall, M.G. Rank Correlation Methods, 4th ed.; Hodder Arnold: London, UK, 1976; ISBN 9780852641996.

54. Mann, H.B. Nonparametric Tests Against Trend. Econometrica 1945, 13, 245-259. [CrossRef]

55. Shadmani, M.; Marofi, S.; Roknian, M. Trend analysis in reference evapotranspiration using Mann-Kendall and Spearman's Rho tests in arid regions of Iran. Water Resour. Manag. 2012, 26, 211-224. [CrossRef]

56. Chen, Y.Z.; Guan, Y.Q.; Shao, G.W.; Zhang, D.R. Investigating trends in streamflow and precipitation in Huangfuchuan Basin with wavelet analysis and the Mann-Kendall test. Water 2016, 8, 77. [CrossRef] 